\title{
Evaluation of Phenamacril and Ipconazole for Control of Rice Bakanae Disease Caused by Fusarium fujikuroi
}

\author{
Meixia Li, Tao Li, Yabing Duan, ${ }^{\dagger}$ Ying Yang, Jian Wu, Donglei Zhao, Xuemei Xiao, Xiayan Pan, Weiwei Chen, Jianxin Wang, \\ Changjun Chen, and Mingguo Zhou, ${ }^{\dagger}$ College of Plant Protection, State \& Local Joint Engineering Research Center of Green Pesticide \\ Invention and Application, Nanjing Agricultural University, Nanjing, 210095, China
}

\begin{abstract}
This study evaluated the use of phenamacril and ipconazole, alone and in mixtures, for the control of rice bakanae disease caused by Fusarium fujikuroi. Mixtures were studied with the goal of reducing the selection of fungicide-resistant field isolates of the fungus. When tested alone, both phenamacril and ipconazole exhibited high antifungal activity against $F$. fujikuroi mycelial growth; the average $\mathrm{EC}_{50}$ value for 19 field isolates was $0.1544 \mu \mathrm{g} / \mathrm{ml}$ for phenamacril and $0.0472 \mu \mathrm{g} / \mathrm{ml}$ for ipconazole. A 2:1 mixture of phenamacril and ipconazole caused a slightly synergistic (greater than additive) inhibition of mycelial growth. Inhibition of $F$. fujikuroi sporulation was highest for ipconazole alone, intermediate with the 2:1 mixture, and lowest for phenamacril

alone. Inhibition by phenamacril and ipconazole alone or by the 2:1 mixture was substantially lower for spore germination than for mycelial growth or sporulation. When the total fungicide concentration was $<24 \mathrm{~g}$ of a.i./100 kg of treated rice seeds, the fungicides, whether alone or in the 2:1 mixture, were not phytotoxic to seeds or seedlings of two rice cultivars. In a greenhouse experiment, the 2:1 mixture of phenamacril and ipconazole at $6 \mathrm{~g}$ of a.i./100 $\mathrm{kg}$ of treated seeds provided $100 \%$ control of rice bakanae disease on two cultivars. Overall, the results indicate that the use of a 2:1 mixture of phenamacril and ipconazole should control rice bakanae disease while reducing the occurrence of fungicide resistance in F. fujikuroi.
\end{abstract}

Rice bakanae disease, caused by Fusarium fujikuroi, is a destructive seed-borne disease in many rice-growing countries (Hsieh et al. 1977; Singh and Sunder 1997). Bakanae disease may affect rice plants from the pre-emergence stage to the mature stage, with severe infection of rice seeds resulting in poor germination or withering (Iqbal et al. 2011). The infected plants are elongated and slender, with long, thin, chlorotic leaves that form abnormally wide angles with stems. Severely infected seedlings often die at early stages. In some cases, bakanae symptoms disappear after the infected seedlings are transplanted in the field but can reappear after the tillering stage. The infection eventually causes plant death or poorly filled or empty grains (Wulff et al. 2010).

Fungicide application is the principal tool for controlling rice bakanae disease. Benzimidazole fungicides (mainly carbendazim) have been widely used to control this disease since the 1980s (Ogawa 1988). Because of the continuous use of carbendazim at high concentrations in recent years, however, carbendazim resistance in $F$. fujikuroi has increased and resulted in control failures in many countries (Chen et al. 2014; Tateishi and Chida 2000).

Phenamacril, a FRAC group code 47 (mode of action: myosin function; http://www.frac.info/), is a novel cyanoacrylate fungicide

${ }^{\dagger}$ Corresponding authors: Y. B. Dual, E-mail: dyb@njau.edu.cn; and M. G. Zhou, E-mail: mgzhou@njau.edu.cn

Funding: This research was supported by the National Key Research and Development Program of China (2016YFD0300706), the Fund for Independent Innovation of Agricultural Science and Technology in Jiangsu Province of China (CX(15)1054), the State-level College Students' Innovative and Entrepreneurial Training Program of China (201710307023), the Special Fund for Agro-scientific Research in the Public Interest (201303023), and the Grant from Innovation Team Program for Jiangsu Universities (2013).

*The $\boldsymbol{e}$-Xtra logo stands for "electronic extra" and indicates that two supplementary figures are published online.

Accepted for publication 9 December 2017.

() 2018 The American Phytopathological Society discovered and patented by the Jiangsu Branch of National Pesticide Research \& Development South Center of China. Phenamacril exhibits specific activity against fungal plant pathogens in the genus Fusarium (Chen et al. 2012; Li et al. 2008). In China, phenamacril is currently registered for the control of wheat head blight caused by $F$. graminearum and rice bakanae disease caused by $F$. fujikuroi. In the previous study, phenamacril-resistant mutants were easily obtained from the wild-type isolates by ultraviolet irradiation and selection. This showed that there was a high risk of phenamacril resistance in Fusarium species (Chen et al. 2008, 2011).

Ipconazole, a FRAC group code 3 (mode of action: sterol biosynthesis; http://www.frac.info/), was synthesized and developed as a fungicide by the Kureha Corporation in 1986 (Saishoji et al. 1998). It functions as a demethylation inhibitor (DMI) of the fungal ergosterol biosynthesis pathway. Ipconazole was first introduced in 1993 in Japan as a seed disinfectant for rice (Eizuka et al. 1994). By 2014, it had been registered and used as a seed disinfectant for cereals, corn, cotton, and other crops in more than 20 countries (Tateishi and Suga 2015).

Recent chemical fungicides have favorable safety and target selectivity profiles. Fungicides with a single mode of action, however, can select for resistance in pathogen populations. The use of the mixture of fungicides with the different action mode can reduce the occurrence of fungicide resistance in plant pathogens and extend the service time of these fungicides (Gisi et al. 1985; Hobbelen et al. 2011). Therefore, the current research assessed mixtures of phenamacril and ipconazole for the control of rice bakanae disease. The specific objective was to determine whether mixtures had additive, synergistic (greater than additive), or antagonistic (less than additive) effects in controlling the pathogen and the disease. Additive effects and especially synergistic effects could potentially delay the selection of individuals with resistance to one component of the mixture (Hobbelen et al. 2011; Mikaberidze et al. 2014).

\section{Materials and Methods}

Fungicides, isolates, and media. Technical grade phenamacril (a.i. 95\%; Jiangsu Branch of National Pesticide Research and Development South Center of China) and ipconazole (a.i. 98.4\%; Chemtura China Holding Co., Ltd.) were dissolved in methanol at $10^{4} \mu \mathrm{g} / \mathrm{ml}$ 
and kept as stock solutions. The phenamacril formulation (25\%, suspension concentrate, SC) was kindly provided by the Jiangsu Branch of the National Pesticide Research and Development South Center of China. The ipconazole formulation (5\%, suspension concentrate, SC) was prepared by our laboratory and consisted of $5 \%$ ipconazole, $1.5 \%$ comb polymer, $2.5 \%$ block copolymer, $0.5 \%$ tridecyl alcohol, $0.6 \%$ bentonite swelling clay, $4 \%$ propylene glycol, $0.2 \%$ xanthan gum, $0.25 \%$ polydimethylsiloxane emulsion, and $85.45 \%$ water.

Nineteen isolates of $F$. fujikuroi were collected from diseased rice seedlings and seeds from different geographical regions in China. The isolates were isolated as single spores and were stored in the Laboratory of Fungicide Biology at Nanjing Agricultural University.

Potato dextrose agar (PDA) was prepared with $200 \mathrm{~g}$ of potato, $20 \mathrm{~g}$ of agar, and $20 \mathrm{~g}$ of dextrose per liter of distilled water. Carboxymethyl cellulose (CMC) was prepared with $15 \mathrm{~g}$ of carboxymethyl cellulose, $0.5 \mathrm{~g}$ of $\mathrm{NH}_{4} \mathrm{NO}_{3}, 0.5 \mathrm{~g}$ of $\mathrm{KH}_{2} \mathrm{PO}_{4}, 0.25 \mathrm{~g}$ of $\mathrm{MgSO}_{4} \cdot 7 \mathrm{H}_{2} \mathrm{O}$, and $0.5 \mathrm{~g}$ of yeast extract per liter of distilled water. Water agar (WA) was prepared with $16 \mathrm{~g}$ of agar powder per liter of distilled water.

Mycelial growth as affected by phenamacril or ipconazole alone or in mixtures. To determine the sensitivity of $F$. fujikuroi to various combinations of phenamacril and ipconazole, mycelial plugs (5 mm diameter) from the edges of 5-day-old colonies were transferred to PDA plates containing a gradient of fungicide concentrations that included a single fungicide (phenamacril or ipconazole alone) or both fungicides with ratios of phenamacril to ipconazole ranging from 1:1 to 16:1 as indicated in Table 1 . After 7 days at $25^{\circ} \mathrm{C}$, colony diameters were measured, and the median effective concentration $\left(\mathrm{EC}_{50}\right)$ for each combination of isolate and fungicide treatment was calculated as previously described (Duan et al. 2013); these are referred to as observed $\mathrm{EC}_{50}$ values in the following section. For the single fungicide treatments (the top two rows in Table 1), all 19 isolates of $F$. fujikuroi were tested. For the mixtures (the remaining rows in Table 1), two of the 19 isolates were randomly selected and tested: XY58 and HLJ01. The isolates XY44 and JR18 were used to further confirm synergistic interaction at the optimal ratio of phenamacril and ipconazole. For the assays with 19 isolates and with four isolates, each combination of isolate and fungicide treatment was represented by three replicate plates, and the assays were repeated.

Synergistic effects of phenamacril and ipconazole on in vitro mycelial growth. As noted in the previous section, the effects of phenamacril and ipconazole alone and in the mixtures indicated in Table 1 were determined for XY58, XY44, JR18, and HLJ01. The interactive effects of the two fungicides were assessed by comparison of observed and expected $\mathrm{EC}_{50}$ values for the four isolates. Observed $\mathrm{EC}_{50}$ values were obtained for single fungicide treatments and mixtures as described in the previous section. Expected $\mathrm{EC}_{50}$ values for mixtures (phenamacril + ipconazole) were calculated as previously described (Gisi 1996; Gisi et al. 1985) and with the following equation: Expected $\mathrm{EC}_{50}=(\mathrm{a}+\mathrm{b}) /\left[\mathrm{a} / \mathrm{EC}_{50}(\mathrm{~A})+\mathrm{b} / \mathrm{EC}_{50}(\mathrm{~B})\right]$, where $\mathrm{a}$ and $\mathrm{b}$ represent the proportion of phenamacril and ipconazole in the mixture, respectively, and $\mathrm{EC}_{50}(\mathrm{~A})$ and $\mathrm{EC}_{50}(\mathrm{~B})$ represent the observed $\mathrm{EC}_{50}$ values of phenamacril and ipconazole, respectively. The synergy ratio (SR) is the ratio of the expected to the observed $\mathrm{EC}_{50}$

Table 1. Concentration gradients used to determine the sensitivity of $F$. fujikuroi to phenamacril and ipconazole alone and in mixtures ${ }^{\mathrm{z}}$

\begin{tabular}{llllll}
\hline Fungicide treatment & \multicolumn{5}{c}{ Concentration gradient $(\boldsymbol{\mu g} / \mathbf{m l})$} \\
\hline Phenamacril (PHE) & 0.0625 & 0.125 & 0.25 & 0.5 & 1.0 \\
Ipconazole (IPC) & 0.03125 & 0.0625 & 0.125 & 0.25 & 0.5 \\
PHE:IPC (1:1) & 0.03125 & 0.0625 & 0.125 & 0.25 & 0.5 \\
PHE:IPC (2:1) & 0.03125 & 0.0625 & 0.125 & 0.25 & 0.5 \\
PHE:IPC (4:1) & 0.0625 & 0.125 & 0.25 & 0.5 & 1.0 \\
PHE:IPC (8:1) & 0.0625 & 0.125 & 0.25 & 0.5 & 1.0 \\
PHE:IPC (16:1) & 0.0625 & 0.125 & 0.25 & 0.5 & 1.0 \\
\hline
\end{tabular}

${ }^{\mathrm{z}}$ Sensitivity was determined based on mycelial growth on Petri plates containing fungicide-amended PDA. Each value in the table indicates the total concentration of fungicide in the PDA. The fungicides alone (top two rows) were tested on all 19 isolates. The mixtures were tested on four of the 19 isolates: XY58, XY44, JR18, and HLJ01. values. When $\mathrm{SR}>1.5$, the interaction is defined as synergistic. When $1.5>\mathrm{SR}>0.5$, the interaction is defined as additive. When $\mathrm{SR}<0.5$, the interaction is defined as antagonistic.

Sporulation as affected by phenamacril or ipconazole alone or in a mixture. Mycelial plugs from the edge of 5-day-old colonies of the isolate XY58 were transferred into CMC media containing each fungicide alone or in mixtures at various final concentrations. The final concentrations tested were $0,0.25,0.5,1.0,2.0$, and $4.0 \mu \mathrm{g} / \mathrm{ml}$ for phenamacril alone; $0,0.009,0.018,0.036,0.0725$, and $0.15 \mu \mathrm{g} / \mathrm{ml}$ for ipconazole alone; and $0.0362,0.0725,0.15,0.3$, and $0.6 \mu \mathrm{g} / \mathrm{ml}$ for the mixture. In the mixture, the ratio of phenamacril to ipconazole was 2:1 (PHE:IPC $=2: 1$ ); this ratio was selected because it had a synergistic inhibitory effect on mycelial growth (see Results). After cultures were kept for 3 days on a rotary shaker $\left(175 \mathrm{rpm}, 25^{\circ} \mathrm{C}\right)$, the number of spores produced in the $\mathrm{CMC}$ medium was determined with a hemocytometer. Each combination of isolate and fungicide treatment was represented by three replicates, and the experiment was repeated.

Spore germination as affected by phenamacril or ipconazole alone or in a mixture. As previously described (Tateishi and Suga 2015), spore suspensions of the isolate XY58 were prepared and diluted to $10^{5}$ spores $/ \mathrm{ml}$. The spore suspensions were evenly spread on WA plates containing each fungicide alone or in a mixture and at various final concentrations. The final concentrations tested were $0,2.5,5$, 10,20 , and $40 \mu \mathrm{g} / \mathrm{ml}$ for phenamacril alone; $0,0.75,1.5,3.0,6.0$, and $12 \mu \mathrm{g} / \mathrm{ml}$ for ipconazole alone; and $0,0.375,0.75,1.5,3.0$, and $6.0 \mu \mathrm{g} / \mathrm{ml}$ for the mixture (PHE:IPC $=2: 1$ ). After the cultures were kept for $8 \mathrm{~h}$ at $25^{\circ} \mathrm{C}$, spore germination was assessed using a light microscope.

Evaluation of phytotoxicity to rice of phenamacril and ipconazole alone or in a mixture. The phytotoxicity test were performed according to the previous study with minor modification (Tateishi and Suga 2015). Fifty grams of rice seeds (cv. Suyunuo and Nanjing 5055) were dipped in $50 \mathrm{ml}$ of the different dilution of each fungicide formulation for $24 \mathrm{~h}$ (Tables 2 and 3 ). As a control, seeds were dipped in water without fungicide. The fungicide-treated and control seeds were soaked in $50 \mathrm{ml}$ of water for an additional $24 \mathrm{~h}$ and divided into two parts. The seeds in one part were tested for germination, and those in the other part were tested for seedling growth as indicated by height and mass. For the germination assay, the seeds were spread on moistened filter paper in a plastic disk. After 5 days at $25^{\circ} \mathrm{C}$ with $85 \%$ relative humidity and a 16 -h daylight photoperiod, the percentage of seeds that germinated was determined. The experiment was performed three times with 300 seeds per combination of cultivar and treatment each time. For the seedling growth assay, the treated seeds were soaked in water at $25^{\circ} \mathrm{C}$ for 2 days to induce germination. The germinated seeds were sown in nursery soil in 0.5 -liter plastic pots (10 seedlings per pot), and the pots were kept in a growth

Table 2. Germination of rice seeds (cvs. Suyunuo and Nanjing 5055) as affected by phenamacril and ipconazole alone or by a 2:1 mixture

\begin{tabular}{|c|c|c|c|c|}
\hline \multirow[b]{2}{*}{ Fungicide } & \multirow{2}{*}{$\begin{array}{c}\text { Concentration } \\
\text { of seed } \\
\text { treatment }^{\mathbf{x}} \\
\left(\mu \mathrm{g} \mathrm{ml}^{-1}\right)\end{array}$} & \multirow[b]{2}{*}{$\begin{array}{c}\text { Dosage }^{y} \\
\text { (a.i. g/100 kg) }\end{array}$} & \multicolumn{2}{|c|}{ Germination rate ${ }^{\mathrm{z}}(\%)$} \\
\hline & & & $\begin{array}{c}\text { cv. } \\
\text { Suyunuo }\end{array}$ & $\begin{array}{l}\text { cv. Nanjing } \\
5055\end{array}$ \\
\hline \multirow[t]{3}{*}{$25 \%$ PHE SC } & 60 & 6 & $97.22 \mathrm{a}$ & $90.89 \mathrm{a}$ \\
\hline & 120 & 12 & $97.33 \mathrm{a}$ & $92.22 \mathrm{a}$ \\
\hline & 240 & 24 & $98.11 \mathrm{a}$ & $92.11 \mathrm{a}$ \\
\hline \multirow[t]{3}{*}{$5 \%$ IPC SC } & 60 & 6 & $97.78 \mathrm{a}$ & $92.67 \mathrm{a}$ \\
\hline & 120 & 12 & $95.78 \mathrm{a}$ & $90.33 \mathrm{a}$ \\
\hline & 240 & 24 & $95.78 \mathrm{a}$ & $91.44 \mathrm{a}$ \\
\hline \multirow[t]{3}{*}{ PHE:IPC (2:1) } & 60 & 6 & $97.11 \mathrm{a}$ & $92.89 \mathrm{a}$ \\
\hline & 120 & 12 & $96.78 \mathrm{a}$ & $90.78 \mathrm{a}$ \\
\hline & 240 & 24 & $98.44 \mathrm{a}$ & $91.33 \mathrm{a}$ \\
\hline CK & - & - & $97.22 \mathrm{a}$ & 90.89 a \\
\hline
\end{tabular}

${ }_{\mathrm{x}}$ This indicates the concentration of active ingredient in fungicide formulation for seed treatment.

${ }^{\mathrm{y}}$ The dosage indicates the quantity of active ingredient used to treat $100 \mathrm{~kg}$ of rice seeds.

${ }^{\mathrm{z}}$ Values are means of three trials with 300 seeds for each combination of treatment, cultivar, and trial. Means followed by the same letter are not significantly different at $P=0.05$. 
chamber at $25^{\circ} \mathrm{C}$ with $85 \%$ relative humidity and a 16-h daylight photoperiod for 21 days before the height and fresh mass of the seedlings were determined. Each combination of treatment and isolate was represented by 100 replicate seedlings, and the assay was performed twice.

Control of rice bakanae disease by phenamacril or ipconazole alone or in a mixture. Rice seeds (cvs. Huajing 5 and Nanjing 5055) were dipped in a suspension of $F$. fujikuroi spores $\left(10^{6}\right.$ spores $\left./ \mathrm{ml}\right)$ of the randomly selected isolate HLJ01 among the 19 isolates for $12 \mathrm{~h}$. The volumetric ratio of the rice seeds to the spore suspension was 1:1. The inoculated seeds were spread on filter paper and dried for $24 \mathrm{~h}$ at room temperature. The seeds were then used for the seed treatment efficacy test.

Fungicide formulations (25\% phenamacril SC, $5 \%$ ipconazole SC, mixture at ratio $2: 5$ of $25 \%$ phenamacril SC and $5 \%$ ipconazole SC) were used. Fifty grams of the inoculated seeds was dipped in $50 \mathrm{ml}$ of water containing the fungicide treatments indicated in Table 4. The seeds in water without fungicide were used as control. After soaking for $24 \mathrm{~h}$, the fungicide-treated seeds were soaked in water for an additional $24 \mathrm{~h}$ (water-soaking) and spread on a moistened filter paper in a plastic dish. After 2 days at room temperature, the germinated seeds were sown in nursery soil in 0.5 -liter plastic pots (10 seeds per pot). The seedlings were kept in the greenhouse until the thirdleaf stage. The incidence of disease was indicated by the percentage of seedlings that damped-off or that became elongated. Each combination of fungicide treatment, isolate, and cultivar was represented by 220 replicate seedlings.

Data analysis. Data were subjected to analysis of variance (ANOVA) using the SAS GLM procedure (SAS Institute, Inc., Cary,
NC). When ANOVA was significant $(P=0.05)$, means were separated with Fisher's protected least significant difference (PLSD).

\section{Results}

Mycelial growth as affected by phenamacril alone and ipconazole alone. Based on inhibition of mycelial growth on PDA, the observed $\mathrm{EC}_{50}$ values for phenamacril alone ranged from 0.0872 to $0.2749 \mu \mathrm{g} / \mathrm{ml}$, and the mean was $0.1544 \mu \mathrm{g} / \mathrm{ml}$ (Fig. 1A). The observed $\mathrm{EC}_{50}$ values for ipconazole alone ranged from 0.0227 to $0.0933 \mu \mathrm{g} / \mathrm{ml}$, and the mean was $0.0472 \mu \mathrm{g} / \mathrm{ml}$ (Fig. 1B). The frequency distribution of $\mathrm{EC}_{50}$ values for the 19 isolates had a normal distribution in the case of phenamacril (Fig. 1A) and a skewed distribution in the case of ipconazole (Fig. 1B).

Synergistic effects of phenamacril and ipconazole mixtures on mycelial growth. Based on the effects of mixtures of phenamacril and ipconazole on the mycelial growth of $F$. fujikuroi isolate XY58, SR values ranged from 0.54 to 1.58 (Table 5). The results indicated a slight synergistic interaction with phenamacril and ipconazole at 2:1. Other ratios were additive. To further assess the synergistic effects of phenamacril and ipconazole at 2:1, the isolate HLJ01 was tested. The results showed that SR values ranged from 0.63 to 1.73 and the interaction of PHE and IPC at 2:1 was also slightly synergistic (Table 6). Two other isolates (XY44 and JR18) were tested at 2:1 of phenamacril and ipconazole and their SR values were 1.64 and 1.61 , respectively. This indicated that, in terms of inhibition of mycelial growth in vitro, the interaction of phenamacril to ipconazole at 2:1 was synergistic for $F$. fujikuroi, i.e., the inhibitory effect of the 2:1 mixture was greater than the additive effect of the fungicides alone.

Table 3. The height and mass of rice seedlings (cvs. Suyunuo and Nanjing 5055) as affected by phenamacril and ipconazole alone or by a 2:1 mixture

\begin{tabular}{|c|c|c|c|c|c|c|}
\hline \multirow[b]{2}{*}{ Fungicide } & \multirow{2}{*}{$\begin{array}{l}\text { Concentration of seed } \\
\text { treatment }^{x}\left(\mu \mathrm{g} \mathrm{ml}^{-1}\right)\end{array}$} & \multirow[b]{2}{*}{ Dosagey $^{y}$ (a.i. g/100 kg) } & \multicolumn{2}{|c|}{ cv. Suyunuo } & \multicolumn{2}{|c|}{ cv. Nanjing 5055} \\
\hline & & & Height $^{\mathrm{z}}$ (cm) & Weight $^{\mathrm{z}}(\mathrm{g})$ & Height $^{\mathrm{z}}$ (cm) & Weight $^{\mathrm{z}}(\mathrm{g})$ \\
\hline \multirow[t]{3}{*}{$25 \%$ PHE SC } & 60 & 6 & $51.67 \mathrm{a}$ & $0.87 \mathrm{a}$ & $49.73 \mathrm{a}$ & $0.75 \mathrm{a}$ \\
\hline & 120 & 12 & $50.95 \mathrm{a}$ & $0.87 \mathrm{a}$ & $51.73 \mathrm{a}$ & $0.79 \mathrm{a}$ \\
\hline & 240 & 24 & $50.22 \mathrm{a}$ & $0.82 \mathrm{a}$ & $49.57 \mathrm{a}$ & $0.71 \mathrm{a}$ \\
\hline \multirow[t]{3}{*}{$5 \%$ IPC SC } & 60 & 6 & $53.95 \mathrm{a}$ & $0.86 \mathrm{a}$ & $51.80 \mathrm{a}$ & $0.77 \mathrm{a}$ \\
\hline & 120 & 12 & $53.60 \mathrm{a}$ & $0.81 \mathrm{a}$ & $52.70 \mathrm{a}$ & $0.77 \mathrm{a}$ \\
\hline & 240 & 24 & $51.10 \mathrm{a}$ & $0.79 \mathrm{a}$ & $51.50 \mathrm{a}$ & $0.73 \mathrm{a}$ \\
\hline \multirow[t]{3}{*}{ PHE:IPC (2:1) } & 60 & 6 & $50.90 \mathrm{a}$ & $0.83 \mathrm{a}$ & $51.10 \mathrm{a}$ & $0.81 \mathrm{a}$ \\
\hline & 120 & 12 & $52.25 \mathrm{a}$ & $0.85 \mathrm{a}$ & $50.87 \mathrm{a}$ & $0.79 \mathrm{a}$ \\
\hline & 240 & 24 & $52.65 \mathrm{a}$ & $0.86 \mathrm{a}$ & $52.67 \mathrm{a}$ & $0.81 \mathrm{a}$ \\
\hline CK & - & - & $50.80 \mathrm{a}$ & $0.82 \mathrm{a}$ & $50.93 \mathrm{a}$ & $0.78 \mathrm{a}$ \\
\hline
\end{tabular}

${ }^{\mathrm{x}}$ This indicates the concentration of active ingredient in fungicide formulation for seed treatment.

${ }^{y}$ The dosage indicates the quantity of active ingredient used to treat $100 \mathrm{~kg}$ of rice seeds.

${ }^{\mathrm{z}}$ Values are means of two trials with 100 seedlings for each combination of treatment, cultivar, and trial. Means followed by the same letter are not significantly different at $P=0.05$.

Table 4. Control of bakanae disease caused by $F$. fujikuroi isolate HLJ01 on two cultivars of rice (cv. Huajing 5 and Nanjing 5055) by phenamacril and ipconazole alone or by a $2: 1$ mixture

\begin{tabular}{|c|c|c|c|c|c|}
\hline \multirow[b]{2}{*}{ Fungicides } & \multirow[b]{2}{*}{$\operatorname{Dosage}^{\mathrm{y}}$ (a.i. g/100 kg) } & \multicolumn{2}{|c|}{ cv. Huajing 5} & \multicolumn{2}{|c|}{ cv. Nanjing 5055} \\
\hline & & Disease incidence (\%) & Efficacy $^{\mathrm{z}}(\%)$ & Disease incidence (\%) & Efficacy $^{\mathbf{z}}(\%)$ \\
\hline \multirow[t]{3}{*}{$25 \%$ PHE SC } & 6 & 2.27 & $92.65 \mathrm{c}$ & 2.73 & $92.41 \mathrm{c}$ \\
\hline & 12 & 0.91 & $97.06 \mathrm{~b}$ & 1.82 & $94.94 \mathrm{bc}$ \\
\hline & 24 & 1.36 & $95.59 \mathrm{bc}$ & 1.36 & $96.20 \mathrm{~b}$ \\
\hline \multirow[t]{3}{*}{$5 \%$ IPC SC } & 6 & 0.91 & $97.06 \mathrm{~b}$ & 3.18 & $91.14 \mathrm{c}$ \\
\hline & 12 & 0.00 & $100.00 \mathrm{a}$ & 0.91 & $97.47 \mathrm{~b}$ \\
\hline & 24 & 0.00 & $100.00 \mathrm{a}$ & 0.00 & $100.00 \mathrm{a}$ \\
\hline \multirow[t]{3}{*}{ PHE:IPC (2:1) } & 6 & 0.00 & $100.00 \mathrm{a}$ & 0.00 & $100.00 \mathrm{a}$ \\
\hline & 12 & 0.00 & $100.00 \mathrm{a}$ & 0.00 & $100.00 \mathrm{a}$ \\
\hline & 24 & 0.00 & $100.00 \mathrm{a}$ & 0.00 & $100.00 \mathrm{a}$ \\
\hline CK & - & 30.91 & - & 35.91 & - \\
\hline
\end{tabular}

$\mathrm{y}$ The dosage indicates the quantity of active ingredient used to treat $100 \mathrm{~kg}$ of rice seeds.

z Values are means of two trials with 220 rice seedlings for each combination of treatment, cultivar, and trial. Means followed by the same letter are not significantly different at $P=0.05$. 
Sporulation as affected by phenamacril or ipconazole alone or in a mixture. Sporulation of isolate XY58 was inhibited by phenamacril, ipconazole, and the 2:1 mixture, and inhibition increased with the total concentration of fungicide in the medium (Fig. 2A). The $\mathrm{EC}_{50}$ values for phenamacril alone, ipconazole alone, and the mixture (PHE:IPC = 2:1) were 1.0466, 0.0263, and $0.0935 \mu \mathrm{g} / \mathrm{ml}$, respectively. The inhibition of sporulation was greater for ipconazole alone and the 2:1 mixture than for phenamacril alone. The SR value of the 2:1 mixture was 0.8 , indicating that the effects were additive.

Spore germination as affected by phenamacril or ipconazole alone or in a mixture. Inhibition of spore germination by phenamacril alone, ipconazole alone, or the mixture increased as the dosages increased (Fig. 2B). At the same fungicide concentrations, inhibition was less for spore germination than for mycelial growth (Fig. 2A and B), i.e., phenamacril and ipconazole had greater effects on mycelial growth than on spore germination.

Evaluation of phytotoxicity to rice as affected by phenamacril or ipconazole alone or in a mixture. The effects of phenamacril and ipconazole (alone and in a 2:1 mixture) on the germination of seeds

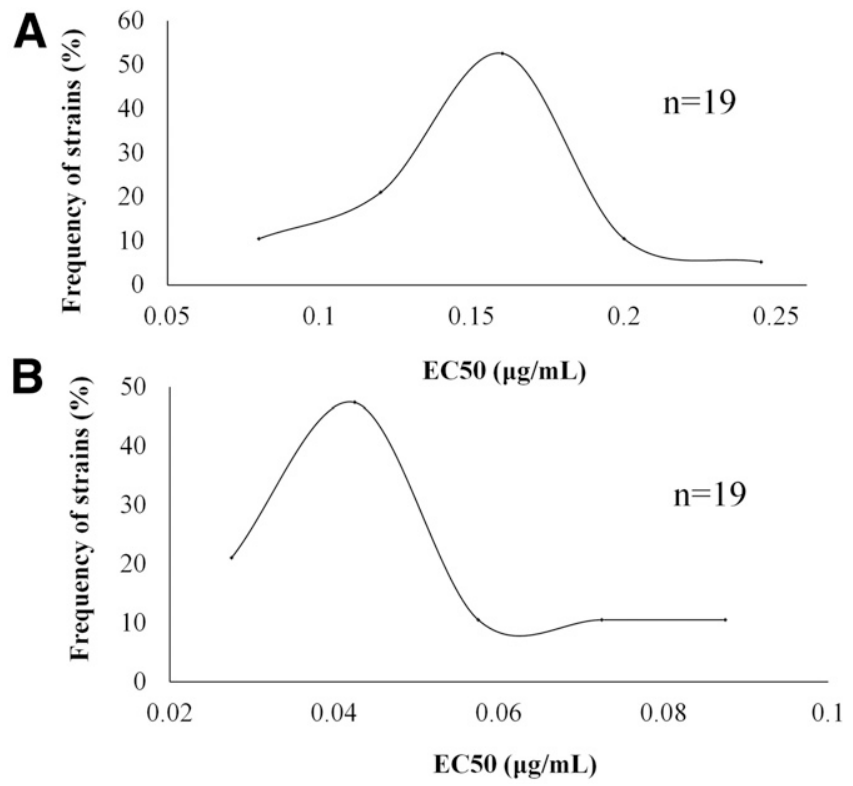

Fig. 1. Frequency distribution of observed $E C_{50}$ values for phenamacril $(\mathbf{A})$ and ipconazole (B) based on inhibition of mycelial growth of 19 isolates of Fusarium fujikuroi. and on the height and fresh mass of seedlings of two rice cultivars (Suyunuo and Nanjing 5055) were determined. Germination of the two cultivars was high and was not significantly affected by the three fungicide treatments (Table 4, Supplementary Fig. S1). The average height of each rice seedling for cvs. Suyunuo and Nanjing 5055 ranged from 50.22 to $53.6 \mathrm{~cm}$ and 49.73 to $52.7 \mathrm{~cm}$, respectively. Neither the height nor the mass of rice seedlings was significantly affected by the fungicide treatments (Table 5, Supplementary Fig. S2).

Control of rice bakanae disease by phenamacril or ipconazole alone or in a mixture. The disease incidences of cultivars Huajing 5 and Nanjing 5055 were $30.91 \%$ and $35.91 \%$ without seed treatment, respectively. Control of rice bakanae disease was greater with the 2:1 mixture of phenamacril and ipconazole than with the single fungicide treatments (Table 6).

\section{Discussion}

Previous research has shown that the novel cyanoacrylate fungicide phenamacril strongly interferes with the mycelial growth of plant pathogens in the fungal genus Fusarium (Chen et al. 2008; $\mathrm{Li}$ et al. 2008). Recent study revealed that myosin 5 was the action target of phenamacril and its specific point mutation regulated phenamacril resistance in the fungal genus Fusarium (Li et al. 2016; Zheng et al. 2015). At present, phenamacril has been registered for the control of rice bakanae disease caused by $F$. fujikuroi in China, but our research indicated phenamacril-resistant mutants were obtained from the wild-type isolates of $F$. fujikuroi by chemical taming. Ipconazole, a demethylation inhibitor (DMI) of the fungal ergosterol biosynthesis pathway, was globally registered and used as a seed disinfectant for cereals, corn, cotton, and other kinds of crops in more than 20 countries as of 2014 (Tateishi and Chida 2000; Tateishi et al. 1998). Ipconazole, however, has not been registered for controlling rice bakanae disease caused by $F$. fujikuroi in China. Surprisingly, the effects of ipconazole on $F$. fujikuroi have rarely been reported. With the goal of reducing the development of phenamacril resistance, the current study determined the effects of phenamacril and ipconazole mixtures that included reduced dosages of phenamacril on $F$. fujikuroi.

To our knowledge, the 19 isolates of $F$. fujikuroi tested in this study had not been previously exposed to ipconazole. These isolates were found to be very sensitive to ipconazole. $\mathrm{EC}_{50}$ values for ipconazole alone ranged from 0.0227 to $0.0933 \mu \mathrm{g} / \mathrm{ml}$, and the mean was $0.0472 \mu \mathrm{g} / \mathrm{ml}$. The results were in accordance with that reported by Tateishi and Suga (2015). For phenamacril sensitivity, EC $_{50}$ values ranged from 0.0872 to $0.2749 \mu \mathrm{g} / \mathrm{ml}$, and the mean $\mathrm{EC}_{50}$ value was $0.1544 \mu \mathrm{g} / \mathrm{ml}$. Similar results were also reported in the previous study (Chen et al. 2012). Although phenamacril has been used to control $F$. fujikuroi in fields for 5 years, the current results indicate that

Table 5. Interactions between phenamacril and ipconazole based on inhibition of mycelial growth of $F$. fujikuroi isolate XY58

\begin{tabular}{lccccc}
\hline Fungicide & Linear regression equation & $\mathbf{R}^{\mathbf{2}}$ & Observed EC $_{\mathbf{5 0}}(\boldsymbol{\mu g} \mathbf{g} \mathbf{m l})$ & Expected EC $_{\mathbf{5 0}}(\boldsymbol{\mu g} / \mathbf{m l})$ & Synergy ratio $^{\mathbf{z}}(\mathbf{S R})$ \\
\hline Phenamacril (PHE) & $\mathrm{y}=5.9076+1.3470 \mathrm{x}$ & 0.9732 & 0.2119 & - & - \\
Ipconazole (IPC) & $\mathrm{y}=6.4273+1.2513 \mathrm{x}$ & 0.9603 & 0.0723 & 0.1078 \\
PHE:IPC (1:1) & $\mathrm{y}=6.5895+1.5865 \mathrm{x}$ & 0.9941 & 0.0996 & 0.1289 \\
PHE:IPC (2:1) & $\mathrm{y}=6.5575+1.4297 \mathrm{x}$ & 0.9820 & 0.0814 & 0.1529 & 1.08 \\
PHE:IPC (4:1) & $\mathrm{y}=6.2961+1.3599 \mathrm{x}$ & 0.9723 & 0.1114 & 0.1745 & 1.58 \\
PHE:IPC (8:1) & $\mathrm{y}=5.7720+1.5943 \mathrm{x}$ & 0.9958 & 0.3254 & 0.1903 & 0.54 \\
PHE:IPC (16:1) & $\mathrm{y}=6.1350+1.6387 \mathrm{x}$ & 0.9928 & 0.2029 & 0.94 \\
\hline
\end{tabular}

${ }^{\mathrm{z}}$ Ratio between expected and observed $\mathrm{EC}_{50}$ values.

Table 6. Interactions between phenamacril and ipconazole based on inhibition of mycelial growth of $F$. fujikuroi isolate HLJ01

\begin{tabular}{lccccc}
\hline Fungicide & Linear regression equation & $\mathbf{R}^{\mathbf{2}}$ & Observed EC $_{\mathbf{5 0}}(\boldsymbol{\mu g} \mathbf{g} \mathbf{m l})$ & Expected EC $_{\mathbf{5 0}}(\boldsymbol{\mu g} / \mathbf{m l})$ & Synergy ratio $^{\mathbf{z}}\left(\mathbf{S R}_{\mathbf{m}}\right)$ \\
\hline Phenamacril (PHE) & $\mathrm{y}=6.0779+1.4247 \mathrm{x}$ & 0.9902 & 0.1752 & - & - \\
Ipconazole (IPC) & $\mathrm{y}=7.1455+1.7144 \mathrm{x}$ & 0.9907 & 0.0560 & 0.0849 \\
PHE:IPC (1:1) & $\mathrm{y}=6.7582+1.5909 \mathrm{x}$ & 0.9841 & 0.0785 & 0.1025 & 1.08 \\
PHE:IPC (2:1) & $\mathrm{y}=6.9782+1.6126 \mathrm{x}$ & 0.9914 & 0.0814 & 0.1229 & 0.1417 \\
PHE:IPC (4:1) & $\mathrm{y}=6.6447+1.5385 \mathrm{x}$ & 0.9956 & 0.1114 & 0.1557 & 1.44 \\
PHE:IPC (8:1) & $\mathrm{y}=6.1815+1.8167 \mathrm{x}$ & 0.9892 & 0.3254 & 0.63 \\
PHE:IPC (16:1) & $\mathrm{y}=6.3124+1.7072 \mathrm{x}$ & 0.9985 & 0.2029 & 0.91 \\
\hline
\end{tabular}

\footnotetext{
${ }^{\mathrm{z}}$ Ratio between expected and observed $\mathrm{EC}_{50}$ values.
} 
phenamacril has a strong inhibition effect on $F$. fujikuroi. These results indicate that the two agents could be used separately to control $F$. fujikuroi, but the use of phenamacril alone could be problematic. As noted earlier, our research has indicated that phenamacril can rapidly select for resistance in $F$. fujikuroi. At present (i.e., only 5 years after phenamacril was first used in China), phenamacril-resistant populations of $F$. fujikuroi (the causal agent of rice bakanae disease) and $F$. graminearum (the causal agent of wheat head blight) have been sporadically discovered in China (Hou et al. 2018). Inhibition of $F$. fujikuroi was greater with ipconazole than with phenamacril in the current study, suggesting that the former fungicide could be useful for controlling rice bakanae disease. To delay the further development of phenamacril resistance, the current study determined whether the antifungal effects of phenamacril-ipconazole mixtures were synergistic, additive, or antagonistic based on in vitro mycelial growth. Ipconazole has a strong inhibition activity on mycelial growth but on spore germination (Figs. 1B and 2B). Moreover, the market price of ipconazole is high. Phenamacril has a strong inhibition effect on both mycelial growth and spore germination (Figs. 1A and 2A) and its market price is low. Based on these advantages, phenamacril has been widely used to control rice bakanae disease by growers. In this study, to improve the application value and reduce the application cost of the mixture of phenamacril and ipconazole on controlling rice bakanae disease in the field, the ipconazole ingredient in the mixture should be decreased. Thus, the specific ratios $(16: 1,8: 1,4: 1,2: 1$, and 1:1) of phenamacril and ipconazole were determined based on mycelial growth. A synergistic effect was detected only with the 2:1 mixture of phenamacril to ipconazole. Based on these results, a mixture of phenamacril and ipconazole at 2:1 is recommended for the control of rice bakanae disease caused by $F$. fujikuroi.

Inhibition of $F$. fujikuroi sporulation increased as the concentration of phenamacril alone or ipconazole alone increased but inhibition was greater with ipconazole than with phenamacril. This was consistent with the results obtained for mycelial growth. In the current study, the effect of a 2:1 mixture of phenamacril and ipconazole on $F$. fujikuroi mycelial growth was synergistic. However, the 2:1 mixture had an additive effect on $F$. fujikuroi sporulation.

Inhibition of $F$. fujikuroi by phenamacril and ipconazole was less on spore germination than on mycelial growth or sporulation. This is consistent with a previous study (Chen et al. 2008) with Gibberella $z e a e$. This is one of the reasons why the determination of synergistic interaction in mixture was based on mycelial growth, not on spore germination.

To provide the information required to register the 2:1 mixture of phenamacril and ipconazole for controlling rice bakanae disease caused by $F$. fujikuroi, the current study assessed the phytotoxicity of the mixture to rice according to the guidelines for crop safety evaluation of pesticides issued by the Ministry of Agriculture of the People's Republic of China. The results indicated that phenamacril alone, ipconazole alone, and the 2:1 mixture of phenamacril and ipconazole were not phytotoxic to rice seed germination or seedling growth when seeds were treated with $<24 \mathrm{~g}$ of a.i./100 $\mathrm{kg}$ of seeds.

Ipconazole is registered and used as a seed treatment for controlling rice bakanae disease caused by $F$. fujikuroi in many countries (Tateishi and Chida 2000; Tateishi et al. 1998), but not in China. In this study, the efficacy of phenamacril and ipconazole seed treatments for control of rice bakanae disease was evaluated using $F$. fujikuroi isolate HLJ01 isolated from diseased rice seedlings in the field. At the same dosage in the current study, ipconazole had a higher efficacy against rice bakanae disease than phenamacril on both of the tested rice cultivars. This result is consistent with the effects of the two fungicides on mycelial growth and spore germination. Although both phenamacril and ipconazole alone provided a high level of rice bakanae disease control, the 2:1 mixture provided $100 \%$ disease control at all three dosages. This indicates that treating seeds with a $2: 1$ mixture of phenamacril and ipconazole at 6 to $12 \mathrm{~g}$ of a.i./100 kg of seed should control rice bakanae disease while reducing the chance of selecting for fungicide resistance in F. fujikuroi.
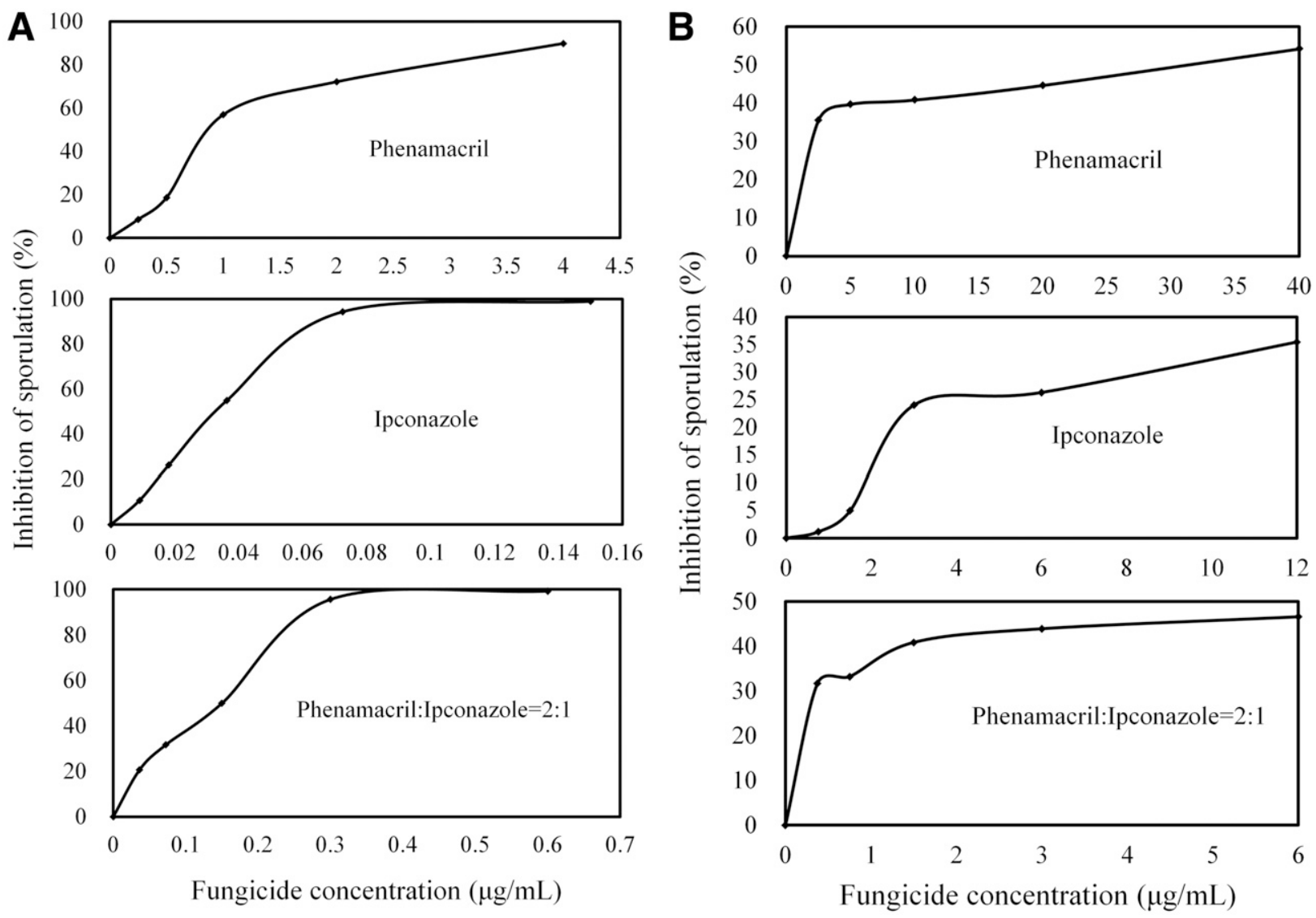

Fig. 2. Sporulation (A) and spore germination (B) of Fusarium fujikuroi isolate XY58 as affected by phenamacril alone, ipconazole alone, and a mixture (PHE:IPC = 2:1). Sporulation and spore germination were assessed on CMC medium and water agar, respectively. 


\section{Literature Cited}

Chen, Y., Huang, T. T., Chen, C. J., Hou, Y. P., Zhang, A. F., Wang, W. X., Gao, T. C., and Zhou, M. G. 2012. Sensitivity of Fusarium verticillioides isolates from rice to a novel cyanoacrylate fungicide. Crop Prot. 39:106-109.

Chen, Y., Li, H. X., Chen, C. J., and Zhou, M. G. 2008. Sensitivity of Fusarium graminearum to fungicide JS399-19: in vitro determination of baseline sensitivity and the risk of developing fungicide resistance. Phytoparasitica 36:326-337.

Chen, Y., Wang, W. X., Zhang, A. F., Gu, C. Y., Zhou, M. G., and Gao, T. C. 2011. Activity of the fungicide JS399-19 against fusarium head blight of wheat and the risk of resistance. Agric. Sci. China 10:1906-1913.

Chen, Z. H., Gao, T., Liang, S. P., Liu, K. X., Zhou, M. G., and Chen, C. J. 2014. Molecular mechanism of resistance of Fusarium fujikuroi to benzimidazole fungicides. Fems Microbiol. Let. 357:77-84.

Duan, Y. B., Ge, C. Y., Liu, S. M., Chen, C. J., and Zhou, M. G. 2013. Effect of phenylpyrrole fungicide fludioxonil on morphological and physiological characteristics of Sclerotinia sclerotiorum. Pestic. Biochem. Physiol. 106: 61-67.

Eizuka, T., Saitoh, K., Chida, T., Satake, K., and Yamaguchi, I. 1994. Metabolism of ipconazole, a new triazole fungicide for seed treatment, in rice plants. J. Pestic. Sci. 19:285-297.

Gisi, U. 1996. Synergistic interaction of fungicides in mixtures. Phytopathology 86:1273-1279.

Gisi, U., Binder, H., and Rimbach, E. 1985. Synergistic interactions of fungicides with different modes of action. Trans. Br. Mycol. Soc. 85:299-306.

Hobbelen, P. H. F., Paveley, N. D., and van den Bosch, F. 2011. Delaying selection for fungicide insensitivity by mixing fungicides at a low and high risk of resistance development: a modeling analysis. Phytopathology 101:1224-1233.

Hou, Y. P., Qu, X. P., Mao, X. W., Kuang, J., Duan, Y. B., Song, X. S., Wang, J. X., Chen, C. J., and Zhou, M. G. 2018. Resistance mechanism of Fusarium fujikuroi to phenamacril in the field. Pest Manag. Sci. 74:607-616.

Hsieh, W. H., Smith, S. N., and Snyder, W. C. 1977. Mating groups in Fusarium moniliforme. Phytopathology 67:1041-1043.
Iqbal, M., Javed, N., Sahi, S. T., and Cheema, N. M. 2011. Genetic management of bakanae disease of rice and evaluation of various fungicides against Fusarium moniliforme in vitro. J. Phytopathol. 23:103-107.

Li, B., Zheng, Z. T., Liu, X. M., Cai, Y., Mao, X. W., and Zhou, M. 2016. Genotypes and characteristics of phenamacril-resistance mutants in Fusarium asiaticum. Plant Dis. 100:1754-1761.

Li, H. K., Diao, Y., Wang, J. X., Chen, C. J., Ni, J. P., and Zhou, M. G. 2008. JS399-19, a new fungicide against wheat scab. Crop Prot. 27:90-95.

Mikaberidze, A., McDonald, B. A., and Bonhoeffer, S. 2014. Can high-risk fungicides be used in mixtures without selecting for fungicide resistance? Phytopathology 104:324-331.

Ogawa, K. 1988. Damage by "Bakanae" disease and its control. Jpn. Pestic. Info. 52:13-15.

Saishoji, T., Ito, A., Kumazawa, S., and Chuman, H. 1998. Structure-activity relationships of enantiomers of the azole fungicide ipconazole and its related compounds: fungicidal and plant growth inhibitory activities. J. Pestic. Sci. 23:129-136.

Singh, R., and Sunder, S. 1997. Foot rot and bakanae of rice: retrospects and prospects. Int. J. Trop. Plant Dis. 15:153-176.

Tateishi, H., and Chida, T. 2000. Sensitivity of Fusarium moniliforme isolates to ipconazole. J. Gen. Plant Pathol. 66:353-359.

Tateishi, H., Saishoji, T., Suzuki, T., and Chida, T. 1998. Antifungal properties of the seed disinfectant ipconazole and its protection against "bakanae" and other diseases of rice. Jpn. J. Phytopathol. 64:443-450.

Tateishi, H., and Suga, H. 2015. Species composition, gibberellin production and sensitivity to ipconazole of the Fusarium fujikuroi species complex isolates obtained before and after its launch. J. Pestic. Sci. 40:124-129.

Wulff, E. G., Sørensen, J. L., Lübeck, M., Nielsen, K. F., Thrane, U., and Torp, J. 2010. Fusarium spp. associated with rice Bakanae: ecology, genetic diversity, pathogenicity and toxigenicity. Environ. Microbiol. 12:649-657.

Zheng, Z., Hou, Y., Cai, Y., Zhang, Y., Li, Y., and Zhou, M. 2015. Whole-genome sequencing reveals that mutations in myosin-5 confer resistance to the fungicide phenamacril in Fusarium graminearum. Sci. Rep. 5:8248. 